biochemical marker for the syndrome has permitted early diagnosis in mildly affected members of a family, leading to treatment with dietary cholesterol replacement, improvement in growth, and control of hyperactivity and other behavioral problems. Pediatricians and pediatric neurologists should have an increased awareness of the variability in the severity of manifestations of SLOS. The diagnosis should be considered in children with unexplained mental retardation or psychomotor delay, especially in those with toe syndactyly, other minor congenital anomalies, and an early history of failure to thrive. Noonan's syndrome is one misdiagnosis reported. Of interest is the frequency of hyperactive behavior in children with SLOS; a child in one report was first diagnosed with ADHD and benefited from treatment with methylphenidate. A normal plasma cholesterol determination does not rule out the diagnosis of SLOS, and measurement of 7-DHC is necessary in suspected cases.

Three articles and reports of cases of SLOS from three different countries, appearing in the current literature, point to the increased interest in the syndrome and its prior lack of recognition. In addition to the two patients reported from Johns Hopkins, three related patients with mental retardation and minimal physical signs are reported from McMaster University, Hamilton, Ontario, Canada (Nowaczyk MJM, Whelan DT, Hill RE. Smith-Lemli-Opitz syndrome: Phenotypic extreme with minimal clinical findings. Am I Med Genet Aug 1998;78:419-423), and three cases of varying severity are analysed genetically at the University of Amsterdam, The Netherlands (Waterham HR, Wijburg FA, Hennekam RCM et al. Smith-Lemli-Opitz syndrome is caused by mutations in the 7dehydrocholesterol reductase gene. Am I Hum Genet Aug 1998;63:329-338).

\title{
FORAMINA PARIETALIA PERMAGNA SYNDROME
}

A boy, born with a soft cranium, had symmetrical defects in the parietal bones, small head, triangular face, micrognathia, small mouth, downslanted palpebral fissures, arched eyebrows, short webbed neck, branchial fistulae, and sensorineural deafness. This case-report from the Children's Memorial Health Institute, Warsaw, Poland, and the Royal Alexandra Hospital for Children, Sydney, Australia, represents a unique branchio-oto syndrome with skeletal abnormalities including foramina parietalia permagna. (Chrzanowska K, Kozlowski K, Kowalska A. Syndromic foramina parietalia permagna. Am I Med Genet Aug 1998;78:401405). (Respond: Dr Kazimierz Kozlowski, New Children's Hospital, PO Box 3515, Parramatta, New South Wales 2124, Australia).

COMMENT. My colleagues in radiology, who were familiar with the coincidental and occasional finding of large symmetrical posterior parietal skull defects in skull X-rays, referred me to Theodore Keats' "Atlas of Normal Roentgen Variants," (Chicago, Year Book Med Publ, 1988). "Foramina parietalia permagna" may occur sporadically, as an inherited dominant trait, or as part of various branchial syndromes. The authors conclude that this case report represents a new branchial syndrome.

In an editorial comment (Syndromal foramina parietalia permagna: "New" or FG syndrome? Comments on the paper by Chrzanowska et al. (1998). Am I Med Genet Aug 1998;78:406-407), Rauch A, Opitz JM, and Walker D opine that, based on our extensive recent experience, the patient has the FG syndrome, an X-linked recessive syndrome of multiple congenital abnormalities and mental retardation, as described by Opitz and Kaveggia in 1974 . However, the Chrzanowska syndrome emphasizes the parietal bone defects and branchial arch fistulae, anomalies that appear to be absent in all but one of the FG syndrome cases. Perhaps the appellation, Opitz-Chrzanowska (OC) syndrome would be a more appropriate 
compromise.

In addition to genetic aspects of congenital syndromes, the importance of environmental factors is apparent from the following report.

Mobius' syndrome and misoprostol attempted abortion. In a study at the Fetal Diagnosis and Treatment Centre, University of Toronto, Canada, among mothers of 96 infants with Mobius' syndrome, 47 (49\%) had used misoprostol in the first trimester of pregnancy, as compared with $3(3 \%)$ mothers of 96 infants with neural-tube defects as controls. Attempted abortion with misoprostol increases risk of Mobius' syndrome in infants (Pastuszak AL, Schuler L, SpeckMartins CE et al. Use of misoprostol during pregnancy and Mobius' syndrome in infants. $\mathrm{N}$ Engl J Med June 25, 1998;338:1881-5).

\section{BILATERAL PERIVENTRICULAR NODULAR HETEROTOPIA}

Two unrelated boys, ages 8 and 5 years, with a syndrome of bilateral periventricular nodular heterotopia $(\mathrm{BPNH})$, regional cortical dysplasia, mild mental retardation, and frontonasal malformation (FNM) are reported from the Instituto di Neuropsychiatria Infantile, University of Pisa, Italy, and the Institute of Human Genetics, University of Minnesota Medical School, Minneapolis, MN. Other manifestations of this BPNH/FNM syndrome, common to both children, included frontal bossing, widow's peak, epicanthal folds, low set ears, and cryptorchidism. The cause is probably genetic, possibly X-linked. (Guerrini R, Dobyns WB. Bilateral periventricular nodular heterotopia with mental retardation and frontonasal malformation. Neurology Aug 1998;51:499-503). (Reprints: Dr Renzo Guerrini, Institute of Child Neurology and Psychiatry, Via dei Giacinti, 2, 56018 Calambrone, Pisa, Italy).

COMMENT. BPNH usually occurs in females with refractory epilepsy and normal intelligence, and a gene mapped to chromosome Xq28. Several other BPNH syndromes are described, affecting males only, and associated with mental retardation and epilepsy but without facial anomalies. Frontonasal malformation (FNM) may occur alone or with intracranial cysts or midline brain defects, including encephalocele, corpus callosum lipoma, and holoprosencephaly, but not BPNH. The above syndrome of BPNH/FNM is unusual.

Multilobar polymicrogyria, drop attack seizures, and sleeprelated electrical status epilepticus is another syndrome reported in 9 patients followed for periods up to 19 years at the University of Pisa, Italy (Guerrini R, Genton P, Bureau M et al. Neurology Aug 1998;51:504-512). Seizures began between 2 and 5 years of age and ceased between 5 and 12 years. The good seizure outcome in these children with polymicrogyria contrasts with most cortical malformations and argues against early surgical intervention.

Lissencephaly, types, radiological grades, and genetic basis, are reviewed from the Medical Genetics Center, Ibn Sina Hospital, Kuwait; and Dalhousie University, Halifax, Canada (Sabry MA, Farah SA, Farag TI, I Am Acad Child Adolesc Psychiatry Sept 1998;37:899). Clinically, lissencephaly is classified as type I (Miller-Dieker syndrome, Norman Roberts syndrome, X-linked, and isolated lissencephaly sequence); type II or cortical dysplasia (congenital muscular dystrophy, Walker-Warberg, Fukuyama syndromes); type III lissencephaly, with corpus callosum agenesis, arthrogryposis, and other anomalies. Radiologically, 6 grades dependent on degrees of agyria, pachygyria, and heterotopic tissue. Genes are mapped to various chromosomes: $17 \mathrm{p} 13,2 \mathrm{p} 11,2 \mathrm{q} 13, \mathrm{Xq} 22$, and 9q31. 